\title{
Flow diagram analysis of electrical fatalities in construction industry
}

\author{
Chia-Fen Chi ${ }^{\text {a, }}$, Yuan-Yuan Lin ${ }^{a}$ and Mohamad Ikhwan ${ }^{\text {a }}$ \\ ${ }^{a}$ Department of Industrial Management, National Taiwan University of Science and Technology, 43 Sec. 4, \\ Keelung Rd., Taipei, 106, Taiwan
}

\begin{abstract}
The current study reanalyzed 250 electrical fatalities in the construction industry from 1996 to 2002 into seven patterns based on source of electricity (power line, energized equipment, improperly installed or damaged equipment), direct contact or indirect contact through some source of injury (boom vehicle, metal bar or pipe, and other conductive material). Each fatality was coded in terms of age, company size, experience, performing tasks, source of injury, accident cause and hazard pattern. The Chi-square Automatic Interaction Detector (CHAID) was applied to the coded data of the fatal electrocution to find a subset of predictors that might derive meaningful classifications or accidents scenarios. A series of Flow Diagrams was constructed based on CHAID result to illustrate the flow of electricity travelling from electrical source to human body. Each of the flow diagrams can be directly linked with feasible prevention strategies by cutting the flow of electricity.
\end{abstract}

Keywords: fatal electrocution, accident analysis, prevention measure, CHAID

\section{Introduction}

Electrical hazards are some of the most dangerous hazards present in construction industry. Many workers are una ware of the potential electrical hazards in their work environment, which increase their vulnerability to the danger of electro cution [1]. Electrical fatalities accounte $\mathrm{d}$ for $14.6 \%$ of all fatal accidents and we re the second lead ing ca use of oc cupational fatality in Taiwan, following falling fatalities.

In our previous study [2], we developed a classification scheme to an alyze 250 fatalities of occupational electrocution in construction ind ustry in terms of age, company size, e xperience, performing, tasks, source of injury, and accide nt causes a nd described these fatalities b ased on Casini (1993)'s five hazard patterns. These five haza rd pat terns of $\mathrm{C}$ asini came from $3 \mathrm{t}$ ypes of el ectrical sources (i.e. power lines, energized e quipment, and damaged or im properly installed equipment) and two major possible ways of electrocution (i.e. direct contact or through in termediary object) $[1,3]$. Casini differentiated contact with energized power lines into direct contact and indirect contact and further divided indirect contact into indirect co ntact $t$ hrough boomed vehicle a nd indi rect contact $\mathrm{t}$ hrough $\mathrm{c}$ onductive material. Ho wever,
Casini had not differentiated electrocution with energized equipment and damaged equipment into direct and indirect c ontact a s his c lassification for contact with power lines. Th erefore, this current study added two new $\mathrm{h}$ azard $\mathrm{p}$ atterns, indirect $\mathrm{c}$ ontact through energized equipment (Pattern 5) a nd indirect contact through damaged e quipment ( Pattern 7) to i mprove the analysis and prevention measures for these two types of accidents. Fig. 1 s hows 7 hazard patterns used in this study.

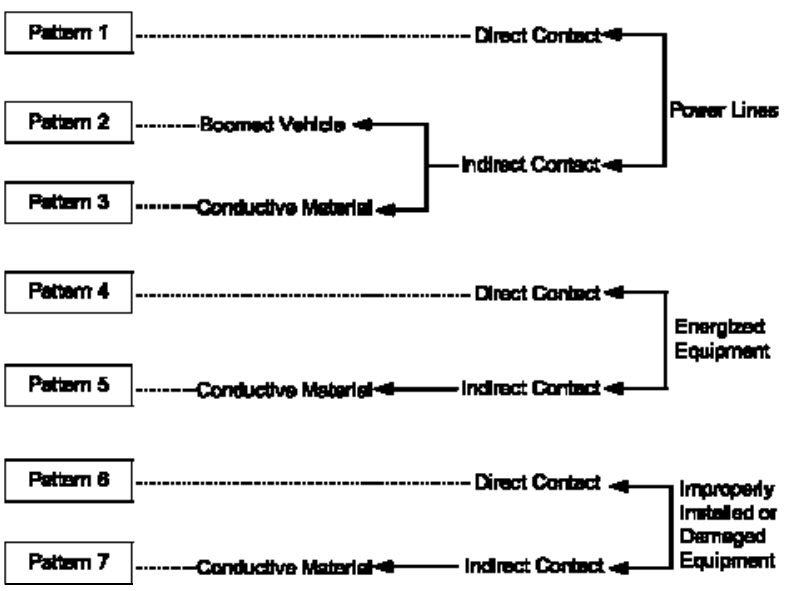

Figure 1. Taxonomy of 7 Hazard Patterns for electrocution

*Corresponding author. E-mail: chris@mail.ntust.edu.tw 
When a person $\mathrm{c}$ omes in $\mathrm{c}$ ontact with electrical agent or vehicle carrying electricity, the flow of electricity passes th rough the person's bo dy so as to complete its path from th e sou rce to $t$ he $g$ round, wherein, human body acts as a conductor of electricity [1]. Oles ke, et al., defined the source of injury as the obj ect, sub stances, ex posure or bod ily motion which directly produced or inflicted the injury [4]. In case of electrocution, the source of i njury is eith er direct c ontact with the elect ricity source or indirect contact with intermediary object or equipment conducting electric current.

Pineault, et al., proposed a Flow Diagram (See Fig. 2) to show possible paths (direct contact or indirect contact $t$ hrough inte rmediary object) bet ween the electrical source $(E S)$ and the victim $(V I)$ in terms of vectors (VE1,VE2, ...VEn) (See Fig. 2) [5]. The idea is to block the electricity flow from electricity source to the victim so as to prevent the electrocution. However, without real example, it was not clear what $V E 1$, $V E 2$, or $V E n$ mean in this model or how th is model can be applied for preventing electrical injury. Therefore, the current research proposed to adopt 250 electrocution fatal ities cases as examples to stu dy and modify the fl ow di agram by repl acing vectors with source of injury (i.e. obj ect that conducts e lectricity to victim from electrical so urce) because the victims were not always working with an electrical source or performing el ectrical $t$ ask. The arrow di rection was also changed from electrical source $t$ o s ource of injury or directly to vi ctim. The fl ow di agram could then be used to propose effective barriers by cutting a trace between electrical sources and the victim [5].

Instead of drawing one flow diagram for e ach fatality case, the se flow diagrams would become more useful, as each flow diagram can denote a significant number of similar fatality cases. Bu t Casini (1993)'s hazard pattern characterized each sce nario only by electrical source and type of contact. In order to draw flow diagrams, these accident patterns must also incorporate source of injury and perhaps other contributing factors. Therefore, CHAID (Chi Square Automatic Interaction Detection) Analysis was ap plied to classify 250 fatality cases i nto lim ited nu mber of meaningful patterns [6] to reduce the number of diagrams that had to be drawn for implementing barriers. In other words, a ge, company size, e xperience, performing, tasks, source of injury, and accide nt causes were used as predictors for differentiating between 7 hazard patterns in orde $r$ to divide all fata lities into several mutually exclusive patterns. In the end, Reliability Blo ck Diagram (RBD) was ad opted in order to inc orporate accident causes into the flow diagram to re veal the best $p$ ossible pre vention $m$ easures di rectly.

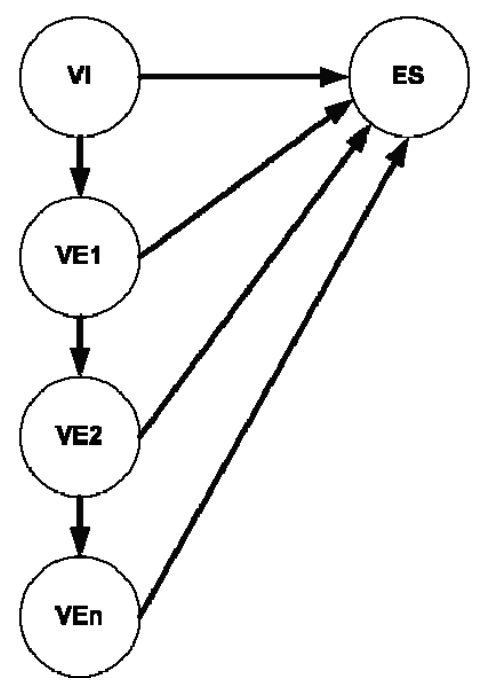

Figure 2 Model for Implementing Barriers [5]

\section{Material and methods}

The c urrent st udy reanalyzed 250 fatal ele ctrocution accidents from 1996 to 2002 [2] usi ng CHAID and Flow Diagram. All accident re ports were e xtracted from case reports th at were published by the Council of Labor Affairs of Taiwan. Each accide nt report identified age, ex perience level of the $\mathrm{v}$ ictim, performing task, s ource of injury, and accident caus es.

\subsection{Chi-square automatic interaction detector (CHAID)}

The C HAID an alysis [7, 8] was app lied to th e coded data of $250 \mathrm{f}$ atal electr ocution accid ents to search through the selected pred ictor variables (age, company size, expe rience, performing tasks, s ource of injury, and accident cause), in order to find a subset of predictors that $\mathrm{m}$ ight expl ain differences between 7 hazard patterns of electrocution.

In the current study of fatal electrocution, source of injury should be the most important predictor for differentiating 7 hazard patterns. Since the sequential order of selected predict or variables was not important, we decided to c onduct C HAID a nalysis usi ng automatic mode. Af ter CHA ID classif ied 250 electrocution fatalities in to mutual exclusive patterns, the flow diagram illustrating potential pathways of elec- 
tric current from electrical source to human body was drawn for each distinguishable pattern.

\subsection{Flow diagram}

Electricity travels i $\mathrm{n} \mathrm{cl}$ osed ci rcuits, thro ugh conductor. As hum an body is an efficient conductor of electricity, whe $n$ it com es in contact with electric flow, it becomes part of the electric [9]. When a person receives a electric shock, electricity flows be tween parts of the body or through the body to a ground or the earth [10]. In the current study, a flow diagram is drawn for each distinguishable pattern to illustrate the "electrical circuit with hu man as one of the conductors in it".

The current study adopted and modified the flow diagram proposed by Pineault et al, 1994 (See Fig. 2) to show possible paths of el ectricity travelling from electrical source ( $E S)$ to t he victim $(V I)$. Each path identified one so urce of i njury ( $S I$ ) (d enoted by a circle) as an object or equipment delivers electric current from source t o victim. The sour ce of i njury was the electrical source responsible for electrocution caused by either direct contact with electrical sou rce or ind irect contact th rough an intermediary object or equipment like metal bar and job ladder.

In order to incorporate the a ccident cause s (denoted by rectangles) into the fl ow di agram [5], this study ad opted the Reliability Block Diagram (RBD) to $s$ how the relationship am ong contributing ca uses based on 250 case reports. In the ori ginal RBD, each block stands for a working physical component and failure of this component was indicated by removal of the corresponding block [11].

In the current study each block has been placed between the el ectrical source and the victim, in the flow diagram to de note one respective ca use of accident that has contributed to the accide ntal electrocution. In other words, each cause block created a potential $p$ ath con necting the victi $m$ an $d$ the electrical source to $\mathrm{m}$ ake $\mathrm{t}$ he elect rocution $\mathrm{h}$ appened. Thus, each caus e block also c orresponds to a fea sible prevention measure. Using RBD format tends to be easier for an analyst to visualize the logic diagram such as fault tree [12]. Generally, there are two main types of connections, i.e. series and $\mathrm{p}$ arallel connections to which 1 ink between $t$ wo or $m$ ore cause blocks. I $n$ case of parallel paths, being redundant i.e. many alternative paths connecting source and victim, at least one of the parallel $\mathrm{p}$ ath $\mathrm{m}$ ust fail for $\mathrm{t}$ he failure of entire network. On $t$ he c ontrary, i n case of series paths, it is $n$ ecessary that all $p$ aths in the series must fail for the failure of network, i.e. for accident to take place [11].

Most fatality cases $\mathrm{h}$ ad multiple causes [13] and there are 3 possible causes $\left(C_{1}, C_{2}\right.$, and $\left.C_{3}\right)$ de rived from all accident reports of a specific accident pattern combined in 3 potential formats $\left(C_{I} C_{2}, C_{I} C_{2} C_{3}\right.$, and $C_{1} C_{3}$ ), for exa mple. An acci dent will take place if any one of the three di fferent combinations occ urs (See Table 1). The $t$ hree different combinations can be si mplified base $\mathrm{d}$ on $\mathrm{B}$ oolean 1 ogic expression $C_{1} C_{2}+C_{l} C_{2} C_{3}+C_{1} C_{3}=C_{1}\left(C_{2}+C_{2} C_{3}+C_{3}\right)=C_{1}\left(C_{2}+C_{3}\right)$ [14]. T he logic expressi on states that accordi ng to logic expression, $\mathrm{C} 1$ will be in series with parallel $C_{2}$ and $C_{3}$. Fig. 3 has shown an example of incorporating 'accident ca uses' in the Table 1, int o the flow diagram for presenting el ectrocution scenarios deri ved from CHAID analysis in terms of fl ow diagram and RBD. The Arrow illustrates an electric curren t flowing from an electrical source $(E S)$ through a source of injury $(S I)$ and passing through the victim $(V I)$. Electrical 'Ground' sym bol below $V I$ and $E S$ rep resents the 'close-loop' leading to an electrocution.

The fl ow diagram in Fig. 3 illu strates th e sequential position of cause blocks between the victim and so urce of injury. $C 1$ indicates an accident ca use (i.e. error) contributed to the electricity flow th rough $S I$ from an ES. Eith er C2 or C3 must be present to cause $\mathrm{t}$ he victim to be elec trocuted through a $S I$. Overall, there are two possible combinations of cause $\left(C_{1}-C_{2}\right.$ and $\left.C_{1}-C_{3}\right)$.

Table 1 An example of coding database for accident causes

\begin{tabular}{|c|c|c|c|}
\hline Case No. & $\mathbf{1}^{\text {st }}$ Cause & $\mathbf{2}^{\text {nd }}$ Cause & $3^{\text {rd }}$ Cause \\
\hline 1 C & 1 & $\mathrm{C}_{2}$ & \\
\hline $2 \mathrm{C}$ & 1 & $\mathrm{C}_{2}$ & $\mathrm{C}_{3}$ \\
\hline $3 \mathrm{C}$ & 1 & $\mathrm{C}_{3}$ & \\
\hline
\end{tabular}

Figure 3 An example of Flow Diagram with one source of injury

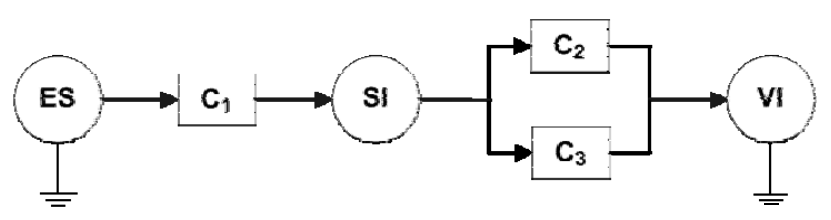




\section{ELECTRICAL SOL'RCE TYPE OF CONTACT SOURCE OF INIJURY}

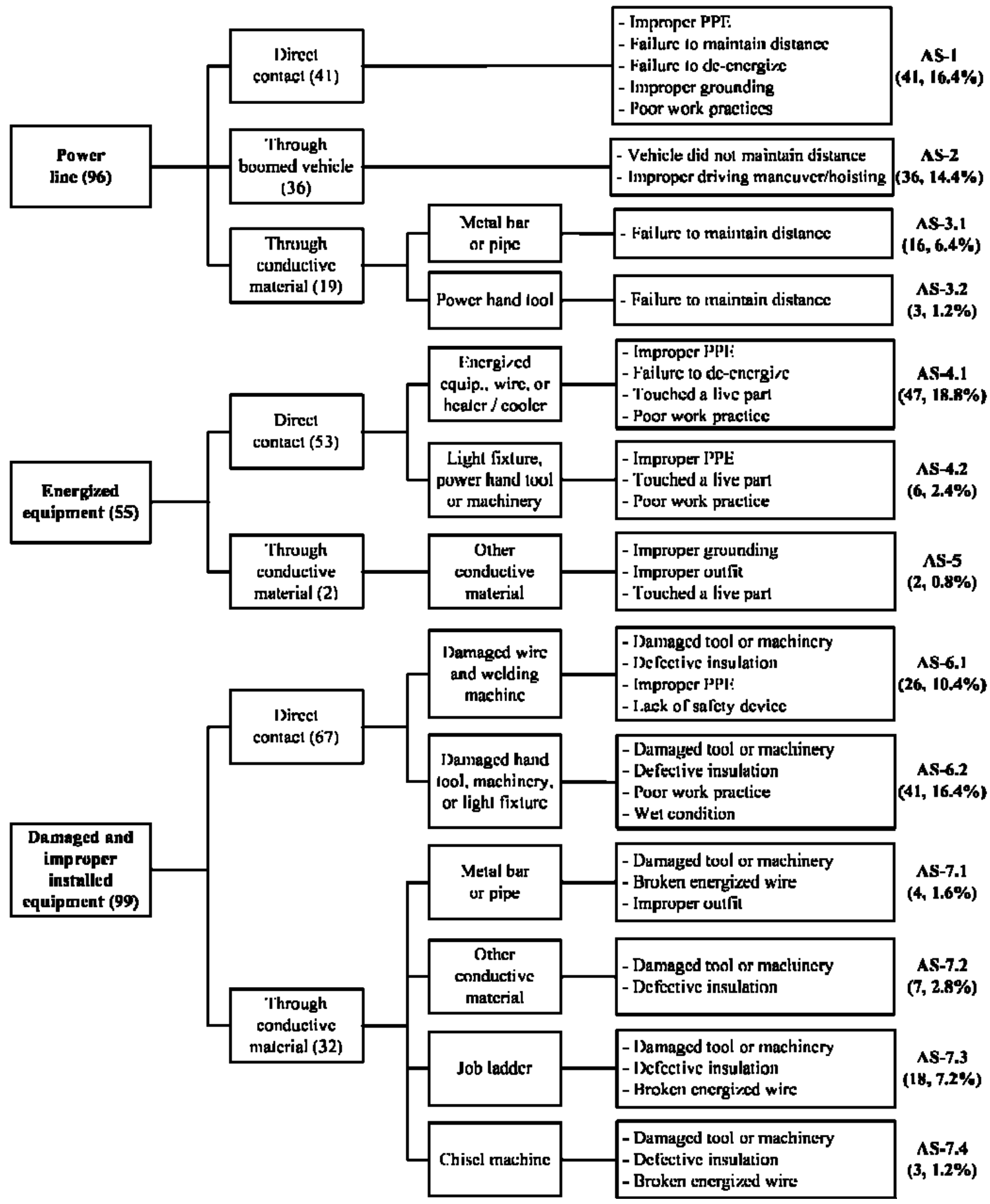

Figure 4. CHAID result for fatal electrocution in Taiwan's construction industry 


\section{CHAID result: the accident scenarios}

CHAID divided total population in to two or more distinct gr oups, base d on categories of $t$ he "best" predictor of a dependent variable (i.e. $t$ he 7 Hazard Pattern), and split each of th ese groups int o smaller subgroups bas ed on ot her predictor vari ables, e.g. accident ca uses. The result of C HAID showed that age, c ompany size, job experience, a nd performing were not fo und to $b$ e significant $p$ redictor $v$ ariables of electrocution. Sources of injury being identified as the "best" or most critical p redictor $(\mathrm{p}<0.001)$ which divided total population in the format of ha zard pattern into nine different groups (nodes). Causes were found to be the second critical pre dictor and it was nested under $t$ he le vels of $t$ he $m$ ost $\mathrm{c}$ ritical factor, source of i njury. The ca uses for electroc ution indicated various possibilities a $\mathrm{v}$ ictim can be electrocuted through the source of injury. Since the resulting accident scenario from CHAID is mainly used for the flow diagram, di fferent acc ident scenarios ca $n$ be merged if they share similar source of injury or accident causes.

As shown in Fig. 4, 13 distinct accident scenarios were generated based on predicting 7 hazard patterns using sign ificant pred ictors, sou rce of i njury, an d cause of accident. Electrical source a nd type of c ontact were added to link the 7 hazard patterns so that each accident scenario can be understood as accident pattern or sub pattern for each accident pattern. For example, hazard pattern 1 a nd 2 were analyzed into accident scenario AS-1 and AS-2, respectively. Hazard pat tern 3 (i.e. indirect $\mathrm{c}$ ontact wit $\mathrm{h}$ powe $\mathrm{r}$ line through co nductive $\mathrm{m}$ aterial) $\mathrm{w}$ as d ivided into t wo distinct accide nt scena rios, AS-3.1 for indirect contact $w$ ith po wer lin e thr ough $m$ etal $b$ ar or $p$ ipe and AS-3.2 for indirect contact with power line th rough power hand tool, respectively.

Distinguishable $g$ roups of ac cident sce nario were used as the ba sis for drawi ng flow diagrams. These accident scenarios are $m$ utually exclusive and exhaustive; such that each scenario did not overlap, and each fatality case belonged to exactly one pattern. By illustrating each scen ario in the fo rm of flow diagrams, it would be very easy to determine the appropriate prevention measures to stop recurre nce of accidents.

Since the CHAID result could be different depending on the coding scheme, each of the hazard scenarios was checked manually to see if a ny of these sce narios can be combined in terms of s ource of injury or acci dent ca use, to re duce com plexity. Regarding hazard pattern 3 i.e., indirect contact with power line, scenario AS-3.1 metal bar or pipe contact with power lines, and sce nario AS-3.2 power ha nd tool co ntact with a power lin e can be combined bec ause both metal bar or pipe and power hand tool share the same nature as sou rce of inj ury. While, in pattern 4, scenario AS-4.1, i.e. direct contact with energized equipment, the direct contact with light wire and heater or cooler machine and scenario AS-4.2, i.e. direct contact with light fixture, power hand tool or machinery can be $\mathrm{c}$ ombined based on sim ilarity of accident causes. Similarly, AS-7.2, AS-7.3 and AS-7.4 or AS6.1 and AS-6.2 can be combined based on the same ground. A ser ies of flow diagram an alysis would be drawn as follows to show distinct accident scenarios after manual combination of similar sources of injury and accident causes.

\section{Some examples of presenting accident scenarios using flow diagram}

Two hun dred and fifty cases w ere an alyzed in to seven accide nt patterns with each containing one to four sce narios. Eac $h$ of the accide nt patt erns wa $s$ elaborated using flow diagram as follows. Notice that for each sce nario, the number of cas es for accident cause does not seem to add up because the inspectors only registered important causes.

\subsection{AS-1: direct worker contact with an energized power line}

In Accident Scenari o 1 (AS-1), victim s directly touched an energ ized power lin e, m ostly wh ile i nstalling, moving o $\mathrm{r}$ rep airing $\mathrm{u}$ tility pole o $\mathrm{r} \mathrm{p}$ ower lines (37 cases out of 41) [2]. Whereas, improper use of PPE ( 25 cases) and failure to de-energize electrical system ( 9 cases), im proper grounding ( 8 cas es), failure to maintain safe distance ( 8 cases) and poor work practices ( 8 ca ses) we re the most co mmon accident causes. Fig. 5 illustrated all possible cause combinations ass ociated with worker directly touched power line without any immediate object.

Based on our database, the five cause blocks were arranged in two parallel series. Th e first parallel series s howed that, proper use of PPE (e.g. helmet, safety gl oves, and sa fety b oots), de-energizing, a nd proper grounding of the power lin e shou ld be don e simultaneously before work in order, to ens ure that, no electrical e nergy from the po wer line could e ndanger the worker. $\mathrm{P}$ roper $\mathrm{g}$ rounding of the po wer 
line was also critical, because 5 victims were electrocuted by back feed voltage from house hold ge nerators. How ever, on ly the power co mpany per sonnel can de-energize the power line, and sometimes, it is not feasible to work out an agreement with the utility company [15]. T herefore, worker m ust put on PPE before $\mathrm{p}$ erforming task on or $\mathrm{n}$ ear $\mathrm{u}$ tility pole. The second parallel series of ca use bl ocks indicate that, poor work practice o $\mathrm{r}$ not main taining safe $d$ istance of body with the live part could electrocute the body parts are not currently covered by PPE.

\subsection{AS-2: boomed vehicle contact with power lines}

All cases in AS-2 had i ndirect electrocution, caused by operating boomed vehicles and failure to maintain safe distances ( 36 cases ), $t$ hen boom touched the power line. Four cases we re a ssociated with p oor work $\mathrm{p}$ ractice, for e.g., improper $\mathrm{d}$ riving maneuver. Fig. 6 illu strated boomed vehicle as th e source of injury to con duct electricity from source (i.e. power line) to the victim. Fai lure to maintain distance and improper driving maneuver were the 2 cause blocks arranged in parallel to i ndicate ei ther one can cause the fatality.

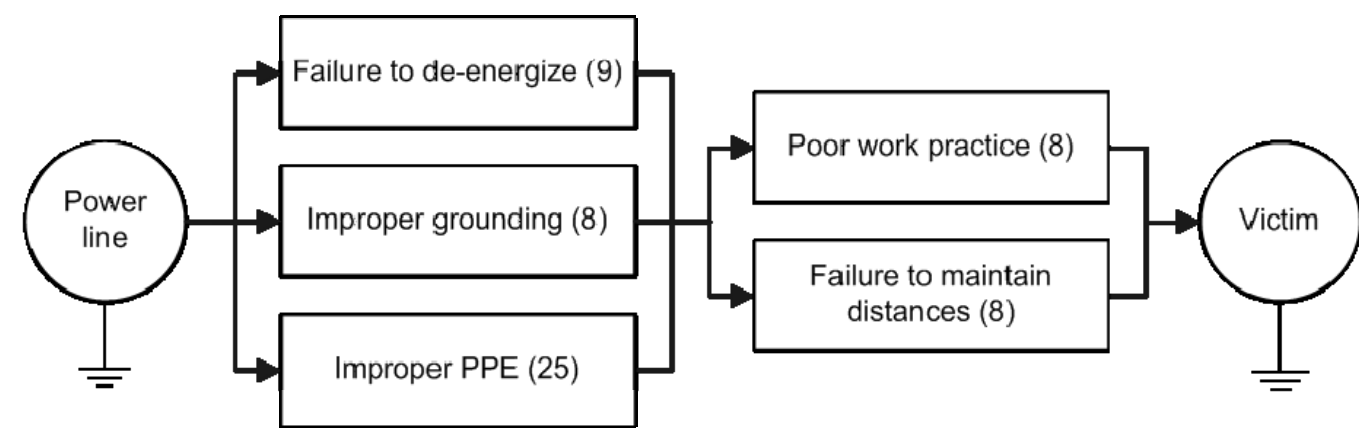

Figure 5 Flow Diagram for hazard pattern 1

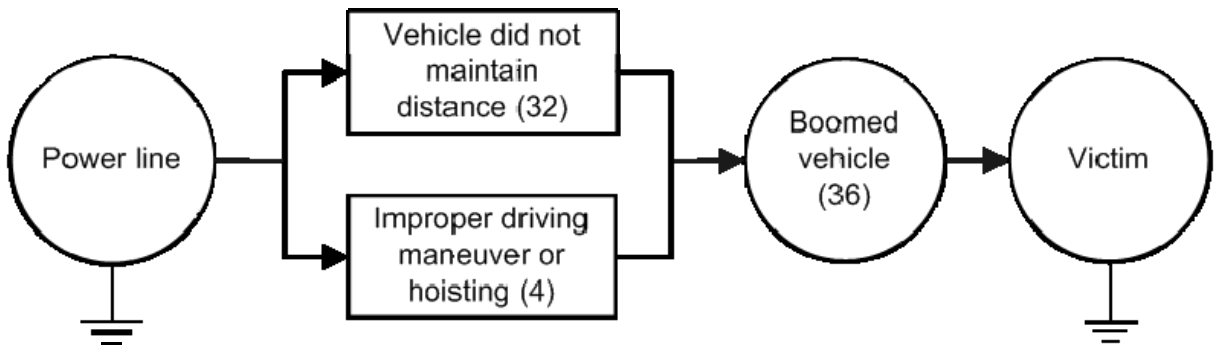

Figure 6 Flow Diagram for hazard pattern 2

\subsection{Hazard pattern 4: direct worker contact with energized equipment}

In case of ha zard pattern 4, victim gets electrocuted $\mathrm{d}$ ue to hi s/her di rect contact with energized equipment such as, distribution box circuit, switches, fuses, and tra nsformer or energize d wire or heater / cooler (AS-4.1), or with 1 ighting fixture, hand tool, or $m$ achinery (AS-4.2). Th ese two scenarios we re combined $\mathrm{b}$ ecause $\mathrm{m}$ ost fatalities sh ared co mmon accident causes including improper PPE (29 cases ), accidentally touched a live part of the electric equipment ( 21 case $\mathrm{s}$ ), and poor work practice (13 case $\mathrm{s})$. On the other hand, these two scena rios were distinguished by different source of electricity; a nd failure to de-energize was the only cause occurred in AS-4.1 because de-energizing procedure such as cleaning the distribution box or replacem ent of s pare parts was not feasible for cases in AS-4.2 (see Fig. 7). 
In hazard pattern 4, acc ording to the case report, each accide nt cause could le ad to an electroc ution fatality b y itself, t hus a 11 accid ent cau ses were arranged in parallel to indicate that all causes should be prevented simultaneously. The number of cases does not seem to add up, because inspect ors c ould ha ve registered o nly im portant $\mathrm{c}$ auses. Besides, as explained in our previous study [2], when two accident causes tied together in a significant number of cases, if the primary cause im plied a seconda ry cause, then only one primary cause was coded to cover the accidental si tuation. T hus o nly poor $\mathrm{w}$ ork practice was coded when $t$ he poor work practice aut omatically lead to touch a live part in 13 cases, so as to reduce redundant causes.

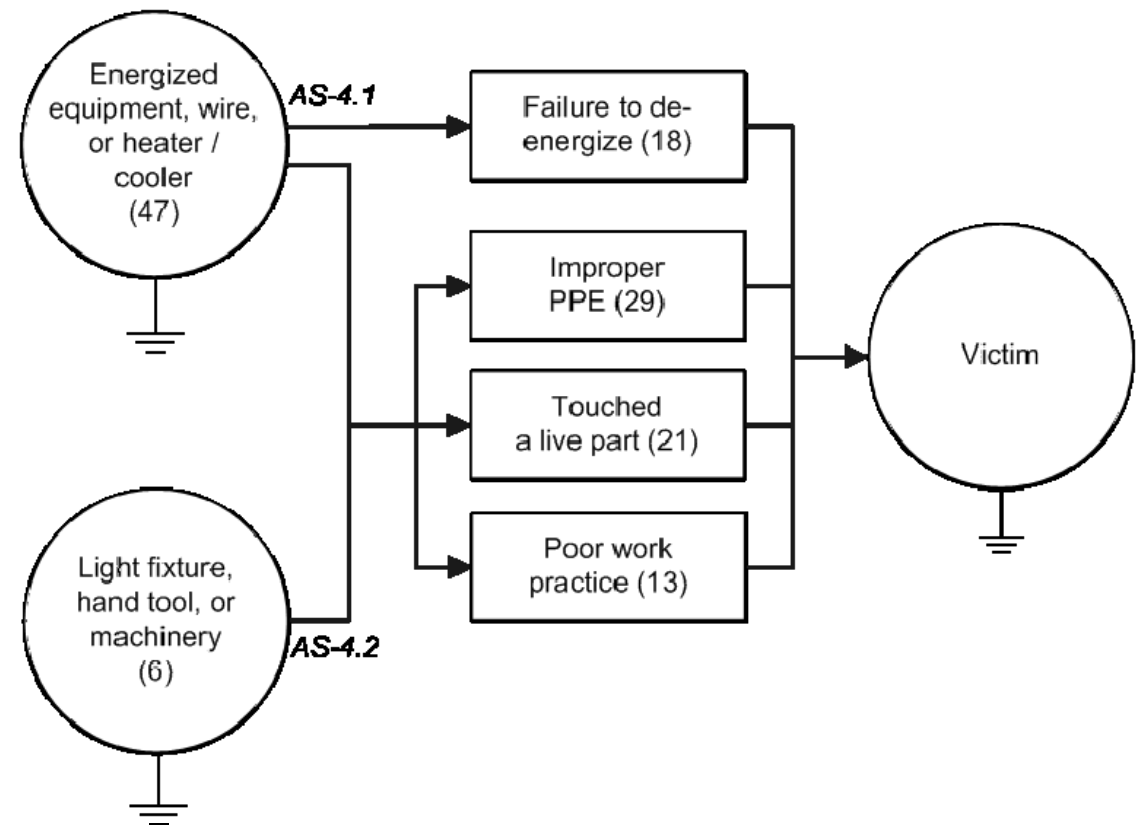

Figure 8 Flow Diagram for hazard pattern 5

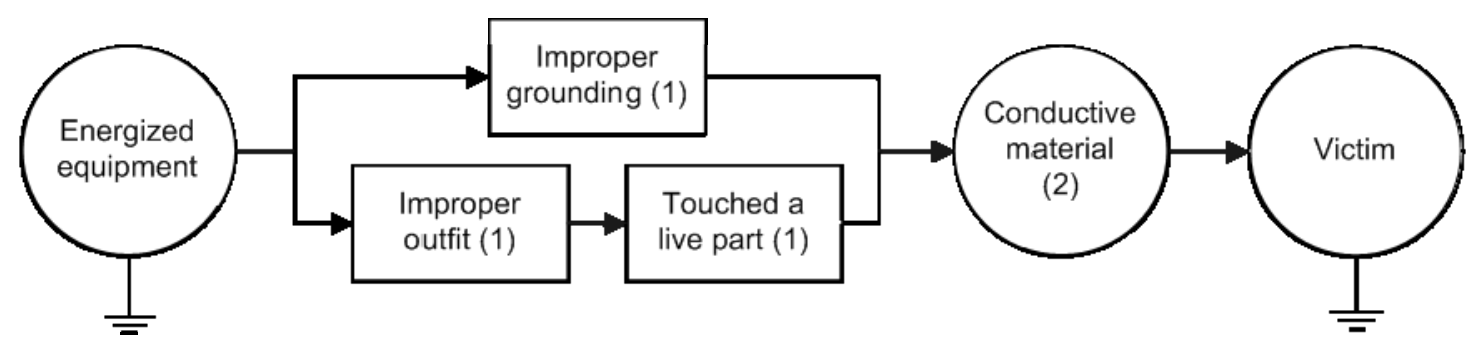

Figure 7 Flow Diagram for hazard pattern 4

\subsection{Hazard pattern 5: indirect worker contact with energized equipment}

As s hown in Fig. 8, there a re only two cases for hazard pattern 5, worker got indirect electrocution by energized equi pment through intermediate co nductive material. One accident was caused by worker's gold nec klace cont acting 1 ive t ransformer w hile working in a stooping position. Another electrocution took place be cause the vic tim touched an e xtinguisher pipe for which another co-worker performed welding on it $\mathrm{w}$ ithout gro unding properly, an $\mathrm{d}$ th $\mathrm{e}$ electricity conducted from the welder electrode to the victim worker through the pipe. 


\section{Conclusion}

Construction workers face a much higher risk of electrocution because they interact with various kinds of machinery, power hand tool with temporary electricity suppl y cabl es, a nd extension c ords st rewn across all ove $r$ the place on the work floors. All of the above situations present very high risk of electrocution accidents to all construction workers. The current study developed flow diagrams proposed by Pineault et al. (1994) bas ed on 250 fatal electroc ution accidents in the $\mathrm{c}$ onstruction i ndustry in Taiwa $\mathrm{n}$. Each of the flow diagrams can be directly linked with feasible prevention strateg ies by cutting the flow of electricity.

Notice that, the flow diagram in this research only illustrated the electrical so urce, the so urce of injury, and the acci dent cause iden tified in 250 fat ality reports. An in spector may identify only obvious or important accide nt causes a nd the inconsist ency be tween in spectors could be the po tential limitation of this stu dy. Also, in consistency in th e repo rt cou ld have hap pened $d$ ue to di fferences in investigation assumptions a dopted by i nspectors a bout causes of accidents and respective pre vention measures [16]. As stated by Svedung \& Rasmussen (2002), graphic representation can $b$ e very effective in creatin $g$ an overview of complex occurrence and also it will b e useful for ef fective c ommunication of ass umptions and findings [17]. The flow diagram based on fatality cases, helps workers and general public to reco gnize the danger of electricity co ming th rough metal $p$ arts and other conducting agents.

\section{References}

[1] Casini, V.J. Occupational electrocutions: investigation and prevention, Professional safety (1993), 34-39.

[2] Chi, C.-F., Yang, C.-C., Chen, Z.-L., In-depth Accident Analysis of Electrical Fatalities in the Construction Industry, International Journal of Industrial Ergonomics 39 (2009), 635-644.
[3] Rossignol M., Pineault M., Classification of fatal occupational electrocutions, Can J Public Health 85 (1994), 322325 .

[4] Oleske, D.M., Brewer, R.D., Doan, P., Jerome, H., An epidemiologic evaluation of the injury experience of a cohort of automotive parts workers: A model for surveillance in small industries, Journal of Occupational Accidents 10 (1989), 239-253.

[5] Pineault, M., Rossignal, M., Barr, R.G. Inter-rater analysis of a classification scheme of occupational fatalities by electrocution, Journal of Safety Research 25(2) (1994), 107-115.

[6] Van Diepen, M., Franses, P.H., Evaluating chi-squared automatic interaction detection, Information Systems 31 (2006), 814-831.

[7] Chi, C.-F., Chen, C.-L., Reanalyzing occupational fatality injuries in Taiwan with a model free approach, Safety Science 41 (2002), 681-700.

[8] Magidson, J. SPSS for Windows, CHAID Release 6.0. SPSS Inc., 1997, pp 1-45.

[9] Masters, G.M. Renewable and Efficient Electric Power Systems. ISBN 0-471-28060-7. John Wiley \& Sons, Inc, 2004.

[10] Occupational Safety and Health Administration (OSHA), Controlling Electrical Hazards. US Department of Labor, OSHA Press, 2002.

[11] Distefano, S., Puliafito, A., DFT and DRBD in Computing Systems Dependability Analysis, Lecture Notes in Computer Science (2007), 423-429.

[12] Pat L. Clemens, Rodney J. Simmons, System safety and risk management, CDC NIOSH, 1998.

[13] Chi, C.-F., Chang, T.-C, Ting, H.-I., Accident patterns and prevention measures for fatal occupational falls in the construction industry, Applied Ergonomics 36 (2005), 391-400.

[14] Robert, N.H., Vesely, W.E., Haasl, D.F., Goldberg, F.F., Fault tee handbook. Washington, DC: US. Government Printing Office, NUREG-0492, 1980.

[15] Janicak, C.A. Occupational fatalities caused by contact with overhead power lines in the construction industry, J Occup Environ Med 39 (1997), 328-332.

[16] Lundberg J, Rollenhagen C, Hollnagel E, What-You-LookFor-Is-What-You-Find - The consequences of underlying accident models in eight accident investigation manuals. Safety Science 47 (2009), 297-311.

[17] Svedung, I., Rasmussen, J., Graphic representation of accident scenarios: mapping system structure and the causation of accidents, Safety Science 40(5) (2002), 397-417. 